TITLE:

\title{
Evaluation of exchange current density for LSM porous cathode based on measurement of three- phase boundary length
}

\section{AUTHOR(S):}

Miyoshi, Kota; Miyamae, Takuma; Iwai, Hiroshi; Saito, Motohiro; Kishimoto, Masashi; Yoshida, Hideo

\section{CITATION:}

Miyoshi, Kota ... [et al]. Evaluation of exchange current density for LSM porous cathode based on measurement of three-phase boundary length. ECS Transactions 2015, 68: 657664

\section{ISSUE DATE:}

2015

URL:

http://hdl.handle.net/2433/218981

\section{RIGHT:}

(C) The Electrochemical Society, Inc. 2015. All rights reserved. Except as provided under U.S. copyright law, this work may not be reproduced, resold, distributed, or modified without the express permission of The Electrochemical Society

(ECS). The archival version of this work was published in [doi: 10.1149/06801.0657ecst ECS Trans. 2015 volume 68, issue 1, 657-664].; This is not the published version. Please cite only the published version.; この論文は出版社版でありません

。引用の際には出版社版をご確認ご利用ください。 


\title{
Evaluation of Exchange Current Density for LSM Porous Cathode Based on Measurement of Three-Phase Boundary Length
}

\author{
Kota Miyoshi ${ }^{\mathrm{a}}$, Takuma Miyamae ${ }^{\mathrm{a}}$, Hiroshi Iwai ${ }^{\mathrm{a}}$, Motohiro Saito ${ }^{\mathrm{a}}$, \\ Masashi Kishimoto ${ }^{a}$, and Hideo Yoshida ${ }^{a}$ \\ ${ }^{\text {a }}$ Department of Aeronautics and Astronautics, Kyoto University, Kyoto 615-8540, Japan
}

Here we propose an empirical formula for the exchange current density per unit TPB (three-phase boundary) length for porous LSM (lanthanum strontium manganite) cathodes for solid oxide fuel cells, which is often required for numerical modeling of cathode performance based on reconstructed microstructures obtained with tomography techniques. Electrochemical measurement of LSM cathodes was conducted under various oxygen partial pressure (0.05-0.25 atm) and temperature (800$950^{\circ} \mathrm{C}$ ) conditions. The derived values were compared with those from a thin and dense patterned LSM electrode in literature, and were found to be small at $800{ }^{\circ} \mathrm{C}$. One of the possible reasons is that the charge transfer can be occurred at not only TPB but also two-phase (LSM-Pore) boundary in the case of thin patterned electrode.

\section{Introduction}

Microstructure of porous electrodes for SOFCs is considered to have a significant effect on their power generation performance because the electrochemical reaction within the electrodes requires sufficient transport of gas species, electrons and oxide ions through the complex multi-phase porous structures. Recent development and improvement of 3D imaging techniques, such as focused ion beam scanning electron microscopy (FIB-SEM) and X-ray computed tomography, has enabled us to obtain detailed electrode microstructures in 3D, which are significantly useful to generate insights on the microstructure-performance relationships.

Three-dimensional datasets of porous electrodes can be also applied to numerical simulations of electrode electrochemical performance (1-7), where a rate equation for the electrochemical reaction is one of the most essential factors that determines the accuracy of the simulation. It was often expressed by Butler-Volmer like forms that include the density of the reaction sites, i.e., three-phase boundary (TPB) or two-phase boundary, and the exchange current density per unit reaction site area/length. The TPB density is considered important in conventional cermet materials such as LSM/YSZ (lanthanum strontium manganite / yttria-stabilized zirconia), while the two-phase boundary in mixed ionic-electronic conductors, such as LSCF (lanthanum strontium cobalt ferrite).

In general, for conventional cermet electrodes, with a metal phase having pure electronic conductivity while a ceramic phase having pure ionic conductivity, the exchange current density per unit ТPB length $\left(i_{0, \mathrm{TPB}}\right)$ was measured from experiments 
using thin and dense patterned electrodes because there is an advantage that TPB length was well-defined from their geometry. However, several works reported discrepancies in the electrode polarization characteristics between experiment and simulation, when they used the empirically derived exchange current density models based on the patterned electrode measurements $(8,9)$. This is due in part to the significant difference in the electrode geometry: porous and patterned.

This study focuses on the electrochemical characteristics of porous LSM cathodes, which have high electrochemical performance at temperature over $900{ }^{\circ} \mathrm{C}$. Although LSM has small ionic conductivity, it can be regarded as pure electron conductor due to the predominant oxygen ion conductivity at the elevated temperatures. To the authors' knowledge, values for the exchange current are available in literatures for patterned LSM electrodes with a thickness of several hundred nanometers (10-12). Radhakrishnan et al. (10) reported correlation between TPB length and charge transfer resistance under various temperature $\left(650-800{ }^{\circ} \mathrm{C}\right)$ and oxygen partial pressure $(0.01-1 \mathrm{~atm})$ conditions using patterned LSM cathodes with a thickness of $500 \mathrm{~nm}$. Brichzin et al. (11) conducted experiments with patterned electrodes with a thickness of 100 and $250 \mathrm{~nm}$, and found that the thickness of the patterned LSM electrodes affects the activation overpotential. Horita et al. (12) observed oxygen diffusion inside the patterned LSM cathode with a thickness of $490 \mathrm{~nm}$ by the secondary-ion mass spectrometry and reported that the oxide ions could be transferred through thin and dense LSM. From these two studies $(11,12)$, it was revealed that the charge transfer could occur at the interface between the LSM phase and the pore phase (two-phase boundary) in thin patterned electrodes. This phenomenon may cause overestimation of $i_{0, \text { TPB }}$ in the experiment with patterned LSM cathodes since the empirical formula for $i_{0, \mathrm{TPB}}$ often assumes that the charge transfer occurs only at TPB. Therefore $i_{0, \mathrm{TPB}}$ can be more accurately derived from LSM cathodes with microstructures similar to actual porous LSM cathodes.

In this study, we conduct electrochemical measurements of porous LSM electrodes to derive an empirical equation for $i_{0, \mathrm{TPB}}$ over a range of temperatures (800-950 ${ }^{\circ} \mathrm{C}$ ) and oxygen partial pressures (5-25\%). An empirical formula for the exchange current density per unit TPB length in porous LSM cathodes is also proposed and compared with those in literature.

\section{Experimental}

The relationships between the charge transfer current $\left(i_{\mathrm{ct}}\left[\mathrm{A} / \mathrm{m}^{2}\right]\right)$ and the activation overpotential $\left(\eta_{\text {act }}[\mathrm{V}]\right)$ are often described by Butler-Volmer like forms $(3,13)$ using TPB density $\left(l_{\text {TPB }}\left[\mathrm{m} / \mathrm{m}^{2}\right]\right)$ and exchange current density per unit TPB length $\left(i_{0, \mathrm{TPB}}\right.$ $[\mathrm{A} / \mathrm{m}])$ :

$$
i_{\mathrm{ct}}=i_{0, \mathrm{TPB}} l_{\mathrm{TPB}}\left[\exp \left(\frac{2 F \eta_{\text {act }}}{R T}\right)-\exp \left(-\frac{2 F \eta_{\text {act }}}{R T}\right)\right]
$$

where $T[\mathrm{~K}]$ is temperature, $F[\mathrm{C} / \mathrm{mol}]$ is the Faraday constantant and $R[\mathrm{~J} /(\mathrm{mol} \mathrm{K})]$ is the gas constant. In order to estimate $i_{0, \mathrm{TPB}}$ experimentally, (i) relationships between the activation overpotential and the charge transfer current and (ii) total TPB length in the 
LSM cathodes used in the power generation experiment are required. Therefore, we conducted power generation experiments with porous LSM cathodes, followed by the 3D analysis of the cathode microstructure with FIB-SEM.

\section{Power Generation Experiment}

The cathode examined in this study was a porous LSM ((La0.8Sr0.2)0.95 $\left.\mathrm{MnO}_{3}\right)$ of a NiYSZ | YSZ | LSM button cell. LSM ink (Fuel Cell Materials) was screen-printed on a YSZ disk electrolyte (Tosoh, $24 \mathrm{~mm}$ in diameter, $500 \mu \mathrm{m}$ in thickness) and sintered at $1150{ }^{\circ} \mathrm{C}$ for $5 \mathrm{~h}$. The thickness of the cathode was ca. 18-20 $\mu \mathrm{m}$ and electrode area was ca. $0.785 \mathrm{~cm}^{2}$. A platinum wire was attached around the side edge of the electrolyte disk

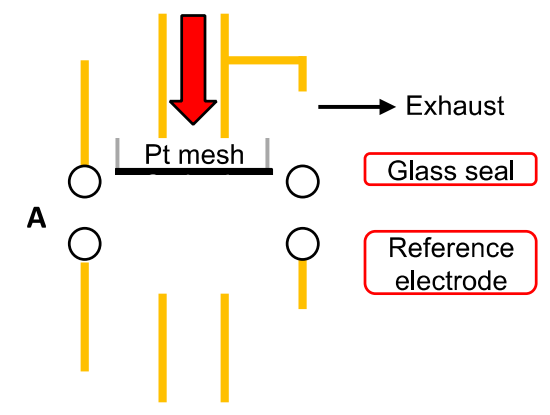

Figure 1. Schematic image of experimental set-up.

(a)

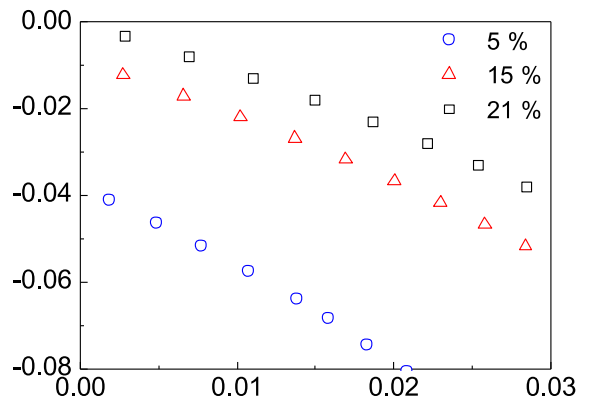

(b)

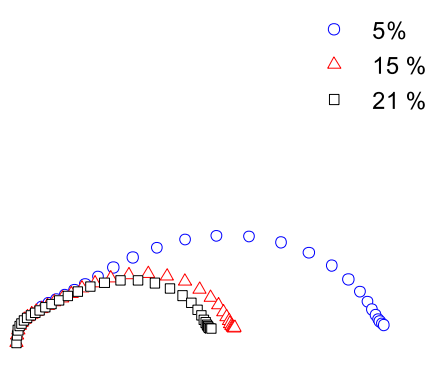

(c)

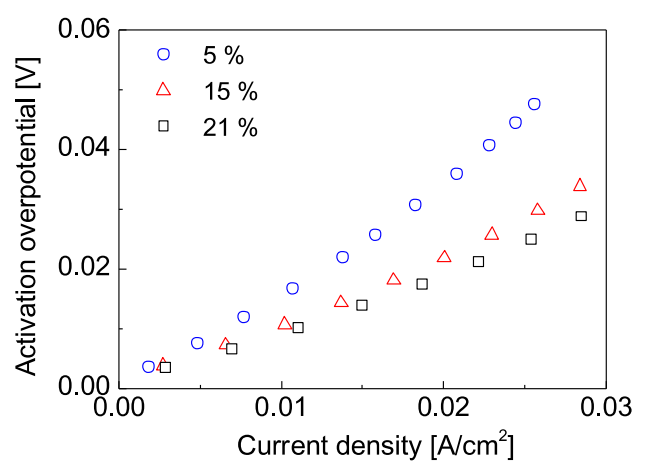

Figure 2. Cathode electrochemical performance measured between the cathode and the reference electrode. (a) $I-V$ characteristics, (b) Nyquist plots at OCV condition and (c) activation overpotential as a function of current density. Operating temperature is $900{ }^{\circ} \mathrm{C}$. 


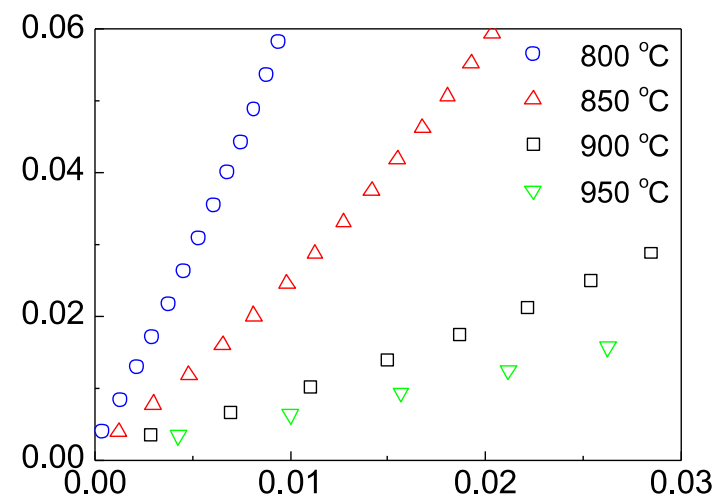

Figure 3. Activation overpotential as a function of the current density with $21 \%$ oxygen.

and used as a reference electrode. Figure 1 shows the schematic image of the experimental set-up. $\mathrm{O}_{2}-\mathrm{N}_{2}$ and $3 \%$ humidified $\mathrm{H}_{2}$ was supplied with a flow rate of $100 \mathrm{ml} / \mathrm{min}$ to cathode and anode, respectively. LSM cathode performance, such as activation overpotentials and ohmic overpotentials was measured by electrochemical impedance spectroscopy (EIS) under various temperature (800, 850, and $950{ }^{\circ} \mathrm{C}$ ) and oxygen concentration (5, 10, 21 and $25 \%$ ) conditions. At $900{ }^{\circ} \mathrm{C}$, the oxygen concentration was varied from $2 \%$ to $25 \%$ with an interval of $2 \%$. In this study, the measurement was conducted under low current density $\left(\sim 0.03 \mathrm{~A} / \mathrm{cm}^{2}\right)$ so that the contribution of the concentration overpotential can be negligible. Figure 2(a) shows the example of the $I-V$ characteristcs of the cathode. Ohmic loss was estimated from the high-frequency intercept of the Nyquist plot (Fig. 2(b)). The polarization overpotential characteristics (Fig. 2(c)) were obtained by subtracting the ohmic loss from the total cathode overpotentials. From this procedure, overpotential dependence on oxygen partial pressure were obtained. We conducted the same procedure over a range of temperatures to obtain temperature dependancy of the polarization overpotentials as shown in Fig. 3.

\section{FIB-SEM Imaging}

After the power generation experiments, 3D microstructure of the sample cathode was obtained using FIB-SEM (Zeiss, NVision 40). The procedure of the FIB-SEM imaging is similar to that employed by Kishimoto et al. (4). For the SEM imaging, an in-lens secondary electron detector was used with an acceleration voltage of $1.5 \mathrm{kV}$. Figure 4(a) shows an example of the obtained cross-sectional SEM images of the cathode. Phase segmentation was conducted on the basis of the brightness difference followed by manual correction. The commercial image processing software AVIZO (FEI) was used for the phase segmentation and 3D reconstruction of the cathode microstructure. As shown in Fig. 4(b), the reconstructed microstructure covers almost the entire thickness of the cathode, with including the interface between the YSZ electrolyte and the LSM cathode. Note that in the LSM cathode, TPB exists only on the electrode-electrolyte interface. Figure 5 shows the TPB distribution on the LSM-YSZ interface. TPB density after the power generation experiment was estimated to be $1.55 \times 10^{6} \mathrm{~m} / \mathrm{m}^{2}$. It has to be noted that the TPB density was evaluated by dividing the total TPB length by the apparent LSMYSZ interface area, $12.1 \times 25.0 \mu \mathrm{m}^{2}$. 
(a)

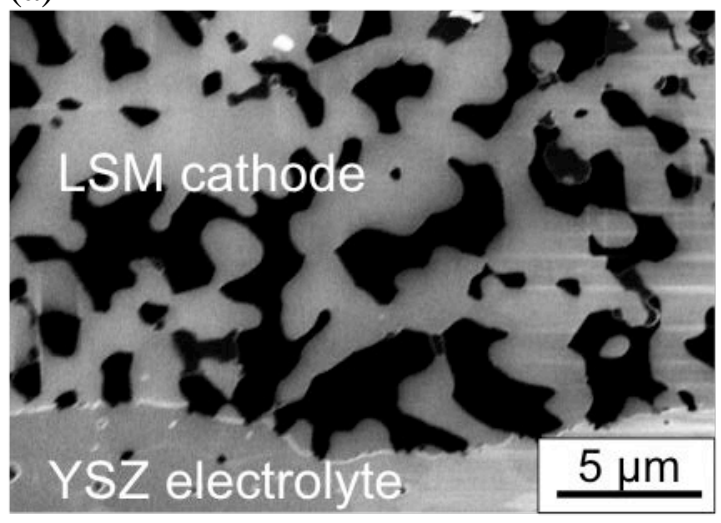

(b)

$12.1 \mu \mathrm{m}$

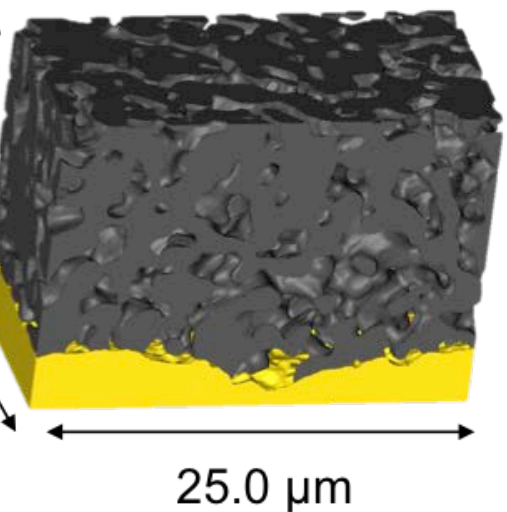

Figure 4. (a) Original SEM image of the LSM cathode. (b) Reconstructed cathode microstructure (Yellow: YSZ, Gray: LSM).

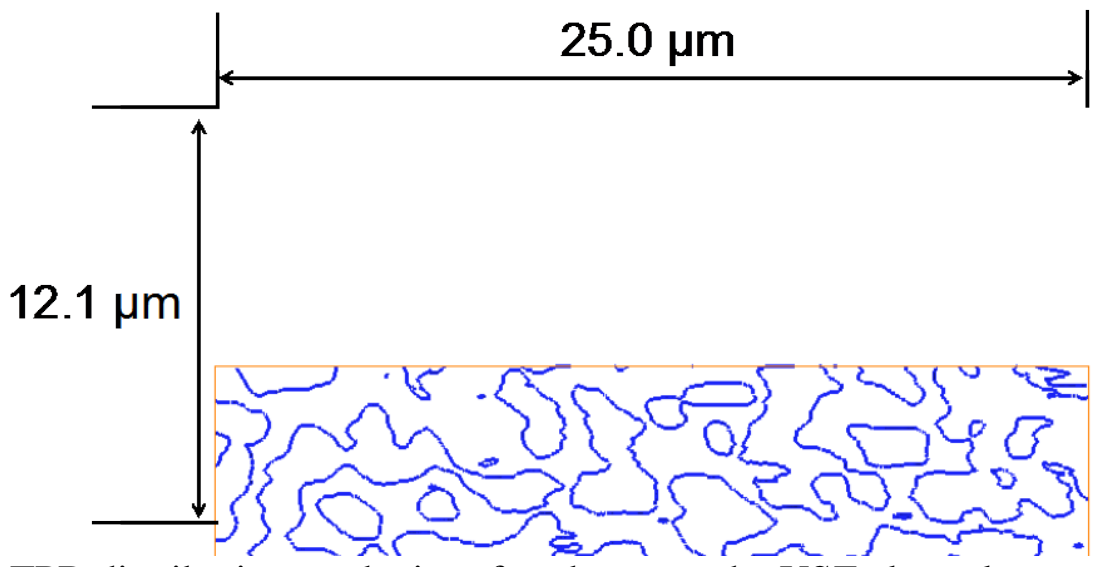

Figure 5. TPB distribution on the interface between the YSZ electrolyte and the LSM cathode.

\section{Results and Discussion}

We assumed (i) the charge transfer reaction occurs only at TPB and (ii) concentration overpotential is negligibly small at lower current denisities. Therefore, $i_{0, \mathrm{TPB}}$ can be estimated experimentally by substituting the charge transfer current density, activation overpotential and TPB density into the eq. 1. In this study, the activation overpotential under ca. $10 \mathrm{~mA} / \mathrm{cm}^{2}$ was used for $i_{0, \mathrm{TPB}}$ estimation. We adopted a power-law equation where $i_{0, \mathrm{TPB}}$ depends on temperature and oxygen partial pressure; $i_{0, \mathrm{TPB}}=$ $A P_{\mathrm{O}_{2}}{ }^{a} \exp \left(\frac{-E}{R T}\right)$ where $P_{\mathrm{O}_{2}}$ [Pa] is oxygen partial pressure, $A, a$ and $E$ are fitting parameters. The fitting method is similar to that employed by Brus et al. (14). Eq. 1 can be rewritten using a reaction constant $k$ as follows:

$$
\begin{gathered}
i_{\mathrm{ct}}=k P_{\mathrm{O}_{2}}{ }^{a} l_{\mathrm{TPB}}\left[\exp \left(\frac{2 F \eta_{\text {act }}}{R T}\right)-\exp \left(-\frac{2 F \eta_{\text {act }}}{R T}\right)\right] \\
k=A \exp \left(-\frac{E}{R T}\right)
\end{gathered}
$$


According to eqs. 2 and 3, the reaction constant $k$ has to be irrespective of the oxygen partial pressure at a given temperature. From the series of measurements conducted at $900{ }^{\circ} \mathrm{C}$ with various oxygen partial pressures, a set of $k$ can be obtained when a certain value is assumed for the exponent $a$. Therefore the exponent $a$ can be determined so that the obtained set of $k$ becomes constant. In reality, however, the value $k$ never becomes constant no matter what value is applied to the exponent $a$, due to the experimental errors. Therefore we defined a relative standard deviation of $k$ as a function of exponent $a$ as follows, and found a value for $a$ to minimize it.

$$
\sigma(a)=\frac{1}{\bar{k}(a)} \sqrt{\frac{1}{N} \sum_{i=1}^{N}\left(k_{i}(a)-\bar{k}(a)\right)^{2}}, \bar{k}(a)=\frac{1}{N} \sum_{i=1}^{N} k_{i}(a)
$$

where $k_{i}(a)$ is the value of $k$ for each oxygen partial pressure condition with a given exponent $a$, and $\bar{k}(a)$ is their average. Figure 6(a) shows the dependency of the $\sigma(a)$ on the exponent $a$, from which the exponent $a$ was determined as 0.376 .

$A$ and $E$ were estimated from the experiments at different temperature conditions with a cathode gas mixture of $\mathrm{O}_{2}: \mathrm{N}_{2}=21: 79$. The obtained value of exponent $a$ was also used. Equation 3 can be rewritten in the Arrhenius form;

$$
\ln k=\ln A-\frac{E}{R T}
$$

Figure 6(b) shows the Arrhenius plot of the experimental results and a fitted linear line obtained with least-square method. The values of $A$ and $E$ were then evaluated from the intercept and the slope of the line, as $2.14 \times 10^{5}$ and -29200 , respectively.

From the analysis above, we derived an empirical equation of $i_{0, \mathrm{TPB}}$ for LSM cathodes as follows:

$$
i_{0, \mathrm{TPB}}=2.14 \times 10^{5} P_{\mathrm{O}_{2}}{ }^{0.376} \exp \left(\frac{-29200}{T}\right)
$$

(a)

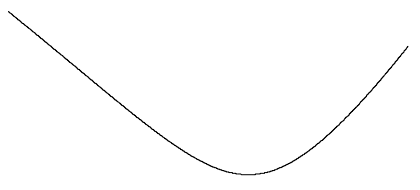

(b)

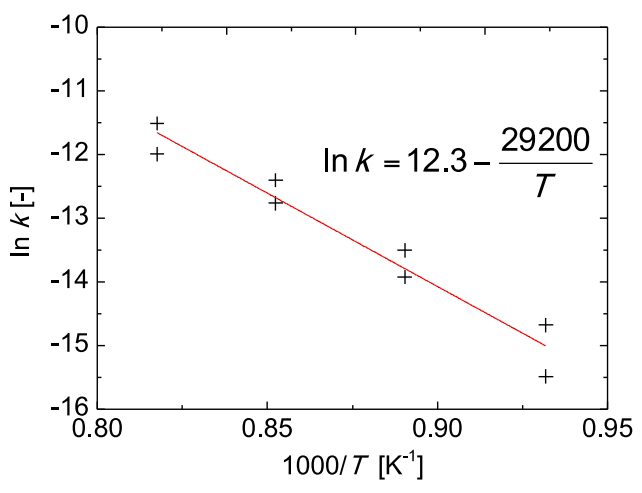

Figure 6. (a) Relative standard deviation of the reaction constant $k$, as a function of the exponent $a$. (b) Arrhenius plot of the experimental results with $21 \%$ oxygen. 
(a)

(b)
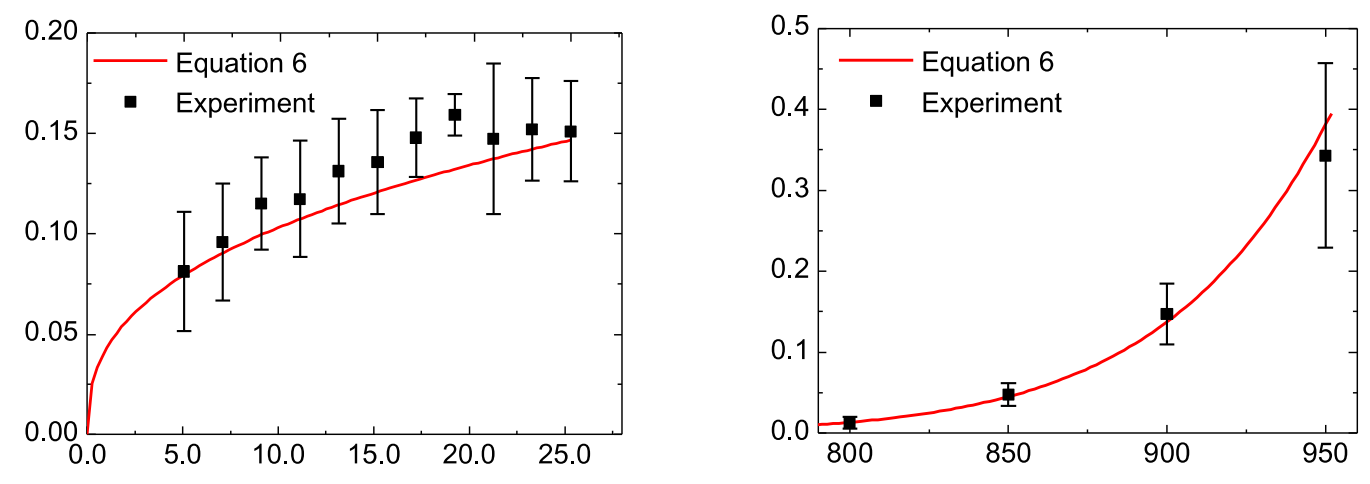

Figure 7. $i_{0, \mathrm{TPB}}$ as a function of (a) oxygen partial pressure at $900{ }^{\circ} \mathrm{C}$ and (b) temperature with $21 \%$ oxygen.

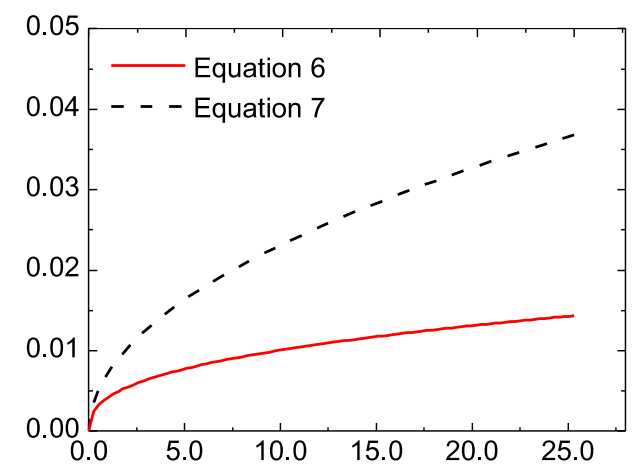

Figure 8. Comparison of $i_{0, \mathrm{TPB}}$ from eq. 6 and eq. 7.

It has to be noted that this equation was derived from the measurements at the temperature of $800-950{ }^{\circ} \mathrm{C}$ and oxygen partial pressure of $5-25 \%$. Figure 7 shows $i_{0, \mathrm{TPB}}$ from eq. 6 and experimentally obtained $i_{0, \mathrm{TPB}}$.

From the experiments with patterned LSM electrodes (10) at the temperature of 650$800{ }^{\circ} \mathrm{C}$ and the oxygen partial pressure of $1-100 \%, i_{0, \mathrm{TPB}}$ was derived by Konno et al. (15) as following empirical equation:

$$
i_{0, \mathrm{TPB}}=1.10 P_{\mathrm{O}_{2}}{ }^{0.5} \exp \left(\frac{-16500}{T}\right)
$$

In order to assess the difference of $i_{0, \text { TPB }}$ between actual porous LSM and patterned LSM, we compared $i_{0, \text { TPB }}$ estimated from eq. 6 and eq. 7 at $800{ }^{\circ} \mathrm{C}$ as shown in Fig. 8. It was found that $i_{0, \mathrm{TPB}}$ from porous LSM was smaller than that from patterned LSM at any condition at $800{ }^{\circ} \mathrm{C}$. The discrepancy between them increased with increasing oxygen partial pressure. For instance, $i_{0, \mathrm{TPB}}$ from eq. 6 was less than one third of that from eq. 7 with a cathode gas mixture of $\mathrm{O}_{2}: \mathrm{N}_{2}=21: 79$. One of the possible reasons is that activation overpotential from the thin electrodes such as patterned electrodes includes the 
effect of not only TPB but also two-phase (LSM-Pore) boundary. For actual LSM or LSM/YSZ composite cathodes using relatively large LSM particles, the equation of $i_{0, \mathrm{TPB}}$ derived in this study can be appropriate.

\section{Conclusions}

In order to derive an equation for the exchange current density per unit TPB length, we obtained the porous LSM cathode performance by electrochemical measurement and its microstructure by FIB-SEM observation. Using these data, dependence of activation overpotential on temperature and oxygen partial pressure were acquired experimentally. From the results, we estimated the exchange current density per unit TPB length using Butler-Volmer like form. The results were fitted into a power-law equation that has temperature and oxygen partial pressure terms by least-square method. Obtained values in this study was smaller than those estimated from patterned electrodes at any oxygen partial pressure in the range of $5-25 \%$ at $800{ }^{\circ} \mathrm{C}$.

\section{Acknowledgments}

This work was supported by the New Energy and Industrial Technology Development Organization (NEDO) under the Development of System and Elemental Technology on Solid Oxide Fuel Cell (SOFC) Project. This work was also supported by Grant-in-Aid for JSPS Fellows.

\section{References}

1. J. R. Wilson et al., Nature Materials, 5, 541-544, (2006).

2. H. Iwai et al., J. Power Sources, 195, 955-961, (2010).

3. M. Kishimoto et al., J. Power Sources, 196, 4555-4563, (2011).

4. M. Kishimoto et al., J. Electrochem. Soc., 159(3), 315-323, (2012).

5. M. Kishimoto et al., J. Power Sources, 223, 268-276, (2013).

6. K. Matsuzaki et al., J. Power Sources, 196, 3073-3082, (2011).

7. T. Carraro et al., Electrochimica Acta, 77, 315-323, (2012).

8. M. Kishimoto et al. Fuel Cells, 13, 476-486, (2013).

9. D. Kanno et al., Electrochimica Acta, 56, 4015-4021, (2011).

10. R. Radhakrishnan et al., J. Electrochem. Soc., 152(1), 210-218, (2005).

11. V. Brichzin et al., Solid State Ionics, 152-153, 499-507, (2002).

12. T. Horita et al., J. Electrochem. Soc., 145(9), 3196-3202, (1998).

13. R. Suwanwarangkul et al., J. Power Sources, 161, 308-322, (2006).

14. G. Brus et al., International Journal of Thermodynamics, 15(1), 43-51, (2012).

15. A. Konno et al., J. Power Sources, 196, 7442-7449, (2011). 